\title{
The impact of microcarrier culture optimization on the glycosylation profile of a monoclonal antibody
}

\author{
Ana Rita Costa ${ }^{1}$, Joanne Withers ${ }^{2}$, Maria Elisa Rodrigues ${ }^{1}$, Niaobh McLoughlin², Mariana Henriques ${ }^{1 *}$, \\ Rosário Oliveira', Pauline M Rudd ${ }^{2}$ and Joana Azeredo ${ }^{1}$
}

\begin{abstract}
Microcarriers are widely used for the large-scale culture of attachment-dependent cells with increased cell densities and, ultimately, higher product yield. In these processes, the specific culture conditions can affect the quality of the product, which is closely related to its glycosylation pattern. Furthermore, the lack of studies in the area reinforces the need to better understand the effects of microcarrier culture in product glycosylation. Consequently, in this work, the glycosylation profile of a monoclonal antibody (mAb) produced by adherent $\mathrm{CHO}-\mathrm{K} 1$ cells grown in Cytodex 3 was evaluated under different conditions, and compared to that obtained of typical adherent cultures. It was found that microcarrier cultures result in a glycosylation profile with different characteristics from T-flask cultures, with a general increase in galactosylation and decrease in fucosylation levels, both with a potentially positive impact on mAb activity. Sialylation also varied but without a general tendency. This study then showed that the specific culture conditions used in microcarrier culture influence the mAb glycan profile, and each functional element (galactose, core fucose, sialic acid) is independently affected by these conditions. In particular, great reductions of fucosylation (from 79 to 55\%) were obtained when using half volume at inoculation, and notable decreases in sialylation (from 23 to 2\%) and glycoform heterogeneity (from 20 to 11 glycoforms) were observed for shake flask culture, potentially associated with the improved cell densities achieved in these culture vessels.
\end{abstract}

Keywords: Microcarrier, Cytodex 3, Glycosylation, Monoclonal antibody, Chinese hamster ovary

\section{Background}

Microcarrier systems are the most well-known technology for the large-scale culture of adherent cells in biotechnology (Chu and Robinson 2001; Kong et al. 1999; Ziao et al. 2002). Indeed, several types of microcarriers have been successfully used for the production of viral vaccines (Berry et al. 1999; Butler et al. 2000; Mendonça et al. 1993; Wu and Huang 2002; Wu et al. 2002) and recombinant proteins (Blüml 2007; Cosgrove et al. 1995; Hu et al. 2000; Wang et al. 2002; Wang and Ouyang 1999), in consequence of an improved surface area available for cell adhesion that results in higher cell density and product yield

\footnotetext{
* Correspondence: mcrh@deb.uminho.pt

'IBB-Institute for Biotechnology and Bioengineering, Centre of Biological Engineering, University of Minho, Campus de Gualtar, 4710-057, Braga, Portugal

Full list of author information is available at the end of the article
}

(Blüml 2007; Hirtenstein et al. 1980; Rudolph et al. 2008; Schürch et al. 1992; Van Wezel 1967). Generally, microcarriers can be divided into microporous (e.g. Cytodex) and macroporous (e.g. CultiSpher, Cytoline, Cytopore), according to the size of the porous, which allow cell growth on the surface or on both surface and inner spaces, respectively (Almgren et al. 1991; Butler 1996; Nilsson et al. 1986; Ozturk and Hu 2006; Spearman et al. 2005; Yokomizo et al. 2004).

The characteristics of the microcarriers are important for the success of the culture (Butler 1996; Ozturk and Hu 2006), but other factors must be considered, such as the size and type of culture vessel (Wang et al. 2002; Wu et al. 1998), and the culture environment (Nam et al. 2008; Ng et al. 1996). Furthermore, it is also important to recognize that the specific conditions of the culture can influence product quality, through effects on protein glycosylation.

\section{实}


Indeed, it has become evident that glycosylation plays critical roles in protein effectiveness in vivo (Jenkins and Curling 1994), and the ability to perform this posttranslational modification is a major reason for the current choice of mammalian cells as hosts for recombinant therapeutic protein production (Nam et al. 2008).

It is therefore essential to ensure that glycosylation of recombinant proteins in microcarrier culture is consistent with the desired product (Spearman et al. 2005). However, to date, there are limited studies examining the effects of changing between adherent, suspension, and microcarrier cultures on glycosylation of the recombinant product (Nam et al. 2008). Furthermore, the few studies performed typically compare microcarrier culture to culture in suspension (Hooker et al. 2007; Wang et al. 2002; Watson et al. 1994), and not to the normal adherent cell culture conditions, and have shown results that seem to be specific to the type of cell, product, and microcarrier used. For example, increased sialylation was found in Cytodex culture for recombinant human tissue kallikrein production (Watson et al. 1994) and in Cytoline culture of Chinese hamster ovary $(\mathrm{CHO})$ cells in a fluidized bed bioreactor for interferon- $\gamma$ production (Hooker et al. 2007), while no differences were found in human recombinant erythropoietin (EPO) produced by $\mathrm{CHO}$ cells in fluidized bed bioreactor cultures with Cytoline (Wang et al. 2002).

In an effort to elucidate the effects of microcarrier culture on protein glycosylation, the present work evaluates the glycan profile of a monoclonal antibody $(\mathrm{mAb})$, with application on cancer therapy, produced by $\mathrm{CHO}-\mathrm{K} 1$ cells grown in microcarriers. Different culture conditions are assessed to determine their influence on $\mathrm{mAb}$ glycosylation, particularly on the galactosylation, fucosylation and sialylation levels, with discussion of their potential impact on the biological effectiveness of the mAb. Additionally, the glycosylation profiles obtained in microcarrier cultures are compared to those of adherent culture in common culture vessels ( $\mathrm{T}$-flasks).

\section{Results and discussion}

An appropriate glycosylation of recombinant proteins, particularly mAbs, is important for their biological activity and clinical efficacy (Spearman et al. 2005). It is therefore essential to ensure that glycosylation in microcarrier cultures is consistent with the desired product. In this study, mAb-producing $\mathrm{CHO}-\mathrm{K} 1$ cells were cultured in microporous Cytodex 3 carriers, under different culture conditions to evaluate their impact on the glycosylation profile of the mAb. Additionally, the glycosylation obtained in microcarrier cultures was compared to that of normal adherent culture conditions in T-flasks. The profiles obtained by normal phase HPLC are shown in Figure 1, and the glucose unit (GU) values and tentative structure assignments of the peaks identified, as well as the relative (\%) peak area obtained in each assay, are shown in Table 1. Glycans found in all conditions are mainly complex biantennary structures with a high degree of heterogeneity, containing different terminal sugars, including sialic acid (S), galactose (G), N-acetylglucosamine (A) and core fucose (F). However, differences can be found between the microcarrier cultures and the typical adherent culture in T-flask in the prevalence of certain glycans, particularly of the most typical IgG1 structures: FA2 (peak 4), FA2G1 (peaks 8 and 9, corresponding to $\alpha 1-6$ and $\alpha 1$ 3-linked fucose, respectively), and FA2G2 (peak 11). Indeed, FA2 and FA2G1 ( $\alpha 1-6)$ show a general tendency to decrease, while FA2G1 ( $\alpha 1-3)$ and FA2G2 levels increase in microcarrier cultures.

The reduction of the prevalence of these main structures in microcarrier culture is obviously accompanied by an increase in the remaining structures, particularly of core fucosylated disialylated glycans such as FA2G2S2 (peak 19) and FA3G3S2 (peak 21), and of A1 (peak 1) and A1G1 (peak 3).

The changes on the mAb glycosylation profile observed between the T-flask and the microcarrier cultures may result from the creation of a different microenvironment for the cells in the microcarriers (Spearman et al. 2005). This may impact glycosylation directly or through variations caused on cell growth characteristics and mAb productivity, such as the ones observed in this study. Effectively, it is clear from Table 2 that microcarriers provide variable cell concentrations, but $\mathrm{mAb}$ productivities are always enhanced when compared to T-flasks. Furthermore, it is known that $\mathrm{CHO}$ cells produce enzymes such as sialidase, beta-galactosidase, and fucosidase that can accumulate extracellularly in culture and potentially lead to extracellular modifications of the glycans (Gramer and Goochee 1993). By affecting cell characteristics, microcarrier culture may also influence the production of such enzymes and potentially interfere with glycosylation.

Furthermore, microcarrier cultures were performed under rocking conditions, which were not present in the typical T-flask cultures, and which may also be a factor leading to the differences found between the glycosylation profile of the $\mathrm{mAb}$ obtained in these two types of cultures.

Several studies have focused on the effect of specific elements of the glycan profile on the effector function of glycosylated proteins. Known as functional elements, these include galactose, core fucose, and sialic acid, and have been shown to influence antibody-dependent cellular cytotoxicity (ADCC) and complement-dependent cytotoxicity (CDC). In fact higher levels of galactosylation (Abès and Teillaud 2010; Hodoniczky et al. 2005; Jefferis and Lund 1997; Serrato et al. 2007), reduced core fucosylation (Shields et al. 2002; Shinkawa et al. 2003; 


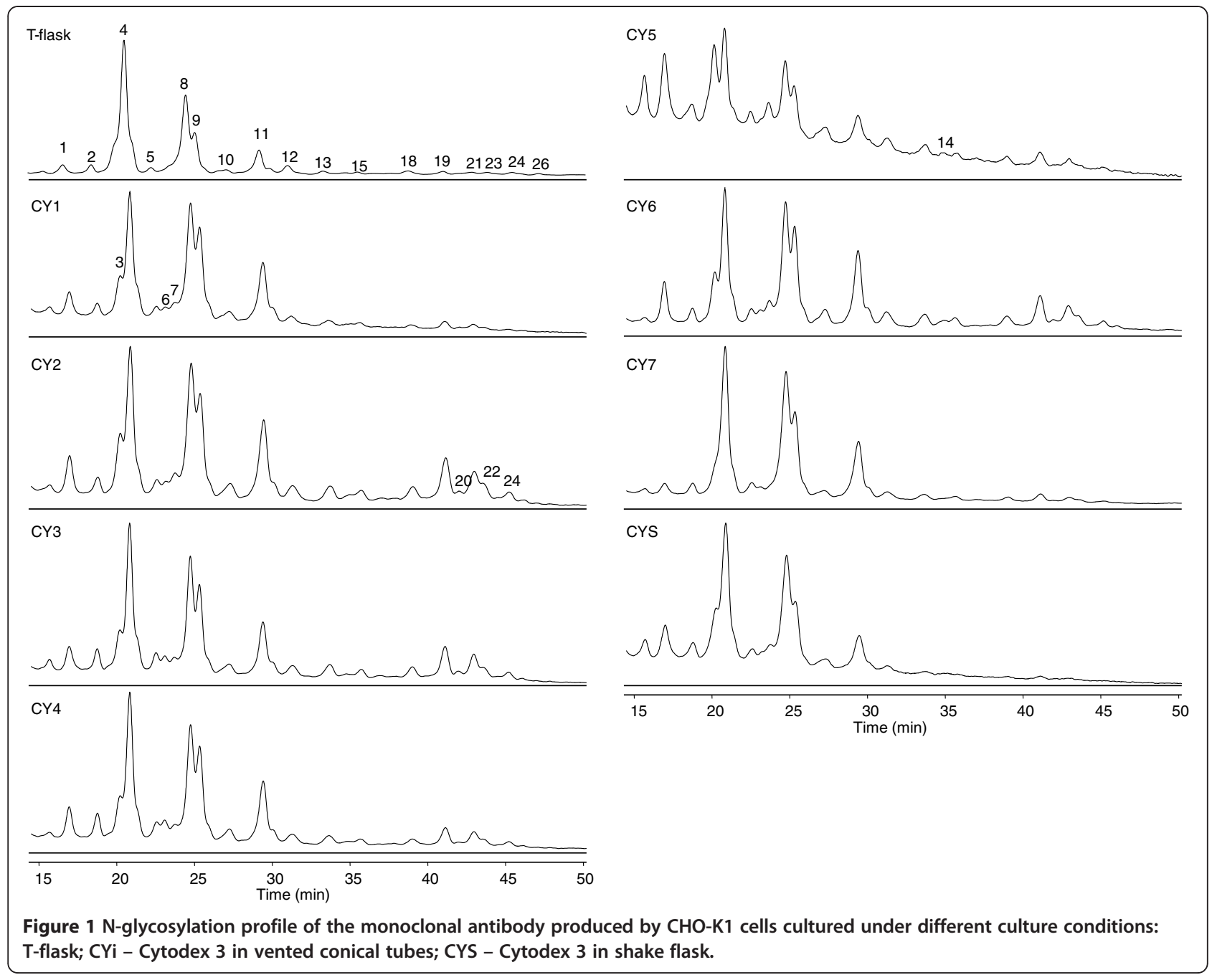

Sibéril et al. 2006) or reduced sialylation (Anthony and Ravetch 2010; Anthony et al. 2008; Kaneko et al. 2006; Scallon et al. 2007) are suggested to enhance the clinical efficacy of mAbs that exert their therapeutic effect by ADCC and CDC mediated killing, such as those used for cancer treatment, including the mAb here assessed. This is particularly relevant for core fucosylation, whose absence can improve ADCC activity by up to 100 -fold (Shields et al. 2002).

The relative percentages of the main functional elements of the mAb produced under the different culture conditions of this study are shown in Table 3. In a first assessment it is possible to detect a general increase of galactosylation (mainly digalacto (G2) and trigalacto (G3) structures) and decrease of fucosylation in microcarrier cultures compared to T-flasks, both having a potential positive effect on mAb activity. On the other hand, although also diverging from the T-flask cultures, the levels of sialylation in the microcarrier assays are more variable, without showing a common tendency, which indicates that this element may be more susceptible to the culture conditions assayed. As mentioned above, it has been shown that $\mathrm{CHO}$ cells produce an extracellular sialidase capable of modifying the sialic acid content of glycoproteins (Gramer and Goochee 1993), and the production/accumulation of this enzyme may be influenced by culture conditions, therefore affecting the degree of sialylation. Additionally, it should be noted that the reported degree of sialylation in human IgG has been below 20\% (Arnold et al. 2007; Pučić et al. 2011; Serrato et al. 2007), but some of the microcarrier cultures showed superior levels (e.g. CY2), mainly due to a higher prevalence of disialylated (S2) structures, both digalacto (S2G2) and trigalacto (S2G3), with potential negative effects on mAb activity by reducing ADCC.

Hypergalactosylation has been associated with low cell densities in previous studies (Kumpel et al. 1994), but there was no correlation found in this work between the higher levels of $\mathrm{mAb}$ galactosylation and the cell densities achieved (Table 2) in microcarrier cultures. For core 
Table 1 Data of mean glucose unit (GU) value, tentative structure assignment, and relative (\%) area of the peaks of the monoclonal antibody produced by CHO-K1 cells under different culture conditions: T-Flask; CYi - Cytodex 3 in vented conical tubes; CYS - Cytodex 3 in shake flask

\begin{tabular}{|c|c|c|c|c|c|c|c|c|c|c|c|}
\hline \multirow[b]{2}{*}{ Peak } & \multirow[b]{2}{*}{ Mean GU } & \multirow[b]{2}{*}{ Tentative assignment } & \multicolumn{9}{|c|}{$\%$ Area } \\
\hline & & & T-Flask & CY1 & $\mathrm{CY} 2$ & $\mathrm{CY} 3$ & CY4 & CY5 & CY6 & $\mathrm{CY7}$ & CYS \\
\hline 1 & $4.9 \pm 0.01$ & A1 & 2.09 & 3.33 & 3.54 & 3.03 & 3.76 & 10.54 & 4.48 & 1.77 & 6.10 \\
\hline 2 & $5.33 \pm 0.01$ & $\mathrm{FA} 1 / \mathrm{A} 2$ & 2.01 & 1.75 & 1.59 & 2.54 & 3.03 & 3.40 & 1.56 & 1.74 & 3.32 \\
\hline 3 & $5.66 \pm 0.01$ & $\mathrm{~A} 1 \mathrm{G} 1$ & - & 5.69 & 5.76 & 5.15 & 5.31 & 14.16 & 5.70 & - & 8.60 \\
\hline 4 & $5.80 \pm 0.01$ & FA2 & 40.99 & 22.01 & 16.59 & 20.59 & 21.24 & 16.93 & 16.87 & 30.92 & 27.57 \\
\hline 5 & $6.18 \pm 0.01$ & $\mathrm{M} 5$ / A2G1 & 1.50 & 1.93 & 1.68 & 2.44 & 2.39 & 3.13 & 1.77 & 2.45 & 2.82 \\
\hline 6 & $6.31 \pm 0.04$ & A2G1[6] & - & 1.61 & 1.19 & 1.97 & 2.55 & - & 1.36 & 1.29 & 4.86 \\
\hline 7 & $6.42 \pm 0.01$ & A2G1[3] & - & 2.34 & 2.49 & 1.82 & 1.88 & 6.22 & 2.77 & - & - \\
\hline 8 & $6.64 \pm 0.01$ & FA2G1[6] & 23.52 & 20.74 & 15.60 & 16.12 & 17.10 & 13.20 & 15.62 & 25.59 & 23.46 \\
\hline 9 & $6.75 \pm 0.01$ & FA2G1[3] & 9.11 & 15.18 & 10.53 & 11.45 & 12.98 & 7.33 & 11.77 & 13.23 & 9.85 \\
\hline 10 & $7.15 \pm 0.02$ & $\mathrm{~A} 2 \mathrm{G} 2 / \mathrm{M} 6$ & 1.65 & 2.59 & 2.15 & 1.94 & 2.37 & 3.25 & 2.72 & 1.81 & 2.59 \\
\hline 11 & $7.59 \pm 0.01$ & FA2G2 & 8.40 & 14.65 & 11.74 & 9.86 & 11.60 & 7.76 & 12.61 & 13.43 & 9.27 \\
\hline 12 & $7.97 \pm 0.01$ & FA2G1S1 & 2.73 & 2.16 & 2.18 & 1.91 & 1.83 & 2.86 & 2.54 & 1.72 & 1.56 \\
\hline 13 & $8.46 \pm 0.01$ & $\mathrm{~A} 2 \mathrm{G} 2 \mathrm{~S} 1$ & 0.91 & 1.29 & 2.12 & 2.03 & 1.58 & 2.44 & 1.98 & 1.09 & - \\
\hline 14 & $8.70 \pm 0.02$ & FA2G2S1[3] & - & - & - & - & - & 0.85 & 1.08 & - & - \\
\hline 15 & $8.88 \pm 0.01$ & FA2G2S1[6] & 0.98 & 1.26 & 2.38 & 2.19 & 1.71 & 0.78 & 1.68 & 1.06 & - \\
\hline 16 & $9.17 \pm 0.02$ & A2G2S2[3] & - & - & - & - & - & - & - & - & - \\
\hline 17 & 9.36 & A3G3S1 & - & - & - & - & - & - & - & - & - \\
\hline 18 & $9.58 \pm 0.01$ & A2G2S2[6] & 1.99 & 0.73 & 3.70 & 2.31 & 1.88 & 1.95 & 2.64 & 0.94 & - \\
\hline 19 & $10.03 \pm 0.01$ & $\mathrm{FA} 2 \mathrm{G} 2 \mathrm{~S} 2$ & 0.95 & 1.25 & 6.43 & 5.66 & 3.17 & 2.84 & 4.94 & 1.54 & - \\
\hline 20 & $10.22 \pm 0.00$ & A3G3S2 & - & - & 1.18 & 1.11 & 0.54 & - & 1.04 & - & - \\
\hline 21 & $10.43 \pm 0.01$ & FA3G3S2[3] & 1.14 & 1.49 & 4.56 & 5.85 & 3.73 & 2.35 & 5.08 & 1.40 & - \\
\hline 22 & $10.56 \pm 0.01$ & FA3G3S2[6] & - & - & 2.05 & - & - & - & - & - & - \\
\hline 23 & 10.68 & FA3G3S2[3,6] & 0.92 & - & - & - & - & - & - & - & - \\
\hline 24 & $10.93 \pm 0.04$ & A3G3S3 & 0.84 & - & 2.54 & 2.01 & 1.34 & - & 1.79 & - & - \\
\hline 25 & $11.12 \pm 0.01$ & A3G3S3[3] & - & - & - & - & - & - & - & - & - \\
\hline \multirow[t]{3}{*}{26} & 11.43 & FA3G3S3 & 0.27 & - & - & - & - & - & - & - & - \\
\hline & & Main structures & 82.02 & 72.58 & 54.46 & 58.02 & 62.92 & 45.22 & 56.87 & 83.17 & 70.15 \\
\hline & & Other structures & 17.98 & 27.42 & 45.54 & 41.96 & 37.07 & 54.77 & 43.13 & 16.81 & 29.85 \\
\hline
\end{tabular}

The main structures are noted in bold.

${ }^{\mathrm{a}}$ Average of the GU value of all samples containing the peak.

fucose, it is interesting to note that in addition to the reduction observed in the total levels of fucosylation, variations are also found in the ratio of agalacto:monogalacto: digalacto:trigalacto (FG0:FG1:FG2:FG3) structures, with a general switch from the FG0 prevalence in T-flask cultures to a FG1 prominence in microcarriers. In both cases, the divergences observed between microcarrier and T-flask cultures may have been caused by the use of rocking in the former.

Furthermore, it should be noted that the potentially better levels (in terms of mAb activity) of each of the functional elements are not obtained in the same conditions. For example, in terms of galactosylation, $\mathrm{mAb}$ with improved characteristics (higher galactose) was produced in CY2; while for fucosylation, the best quality
$\mathrm{mAb}$ (less core fucose) was obtained in CY5; and for sialylation, the lower and best levels were obtained in CY1, CY7, and CYS.

It has been suggested that increases in productivity, such as the ones observed in the microcarrier cultures, may potentially lead to decreased effectiveness of recombinant proteins (Nam et al. 2008). However, in this work, the increased productivities of microcarrier cultures (Table 2) do not seem to correlate with a lower quality of the mAb.

In a more specific analysis, the different conditions evaluated for the microcarrier cultures were considered. Rocking speed influences the mAb glycosylation profile, but this effect is highly dependent on the rocking methodology. For example, when using pulse/continuous 
Table 2 Data of average cell concentration and productivity of monoclonal antibody-producing CHO-K1 cells cultured in different conditions: T-flask; CYi - Cytodex 3 in vented conical tubes; CYS - Cytodex 3 in shake flask

\begin{tabular}{|c|c|c|}
\hline Assay & $\frac{\text { Av. viable cell conc. }}{\left(\mathrm{x} 10^{5} \text { cells } / \mathrm{mL}\right)}$ & $\frac{q_{\mathrm{mAb}}}{(\mathrm{pg} / \text { cell/day })}$ \\
\hline T-flask & $8.51 \pm 0.06$ & $0.21 \pm 0.05$ \\
\hline $\mathrm{CY} 1$ & $6.86 \pm 1.06$ & $2.57 \pm 1.38$ \\
\hline $\mathrm{CY} 2$ & $16.02 \pm 1.98$ & $0.84 \pm 0.35$ \\
\hline $\mathrm{CY} 3$ & $3.73 \pm 0.63$ & $3.89 \pm 1.17$ \\
\hline $\mathrm{CY} 4$ & $6.21 \pm 0.62$ & $2.16 \pm 0.94$ \\
\hline CY5 & $7.63 \pm 0.76$ & $1.75 \pm 0.66$ \\
\hline $\mathrm{CY} 6$ & $18.51 \pm 1.08$ & $1.26 \pm 0.99$ \\
\hline $\mathrm{CY} 7$ & $10.25 \pm 0.73$ & $1.51 \pm 0.30$ \\
\hline CYS & $104.1 \pm 6.00$ & $1.86 \pm 0.58$ \\
\hline
\end{tabular}

Table 3 Galactose, core fucose and sialic acid composition of the monoclonal antibody produced by CHO-K1 cells during microcarrier culture in different conditions: T-flask; CYi - Cytodex 3 in vented conical tubes; CYS - Cytodex 3 in shake flask

\begin{tabular}{|c|c|c|c|c|c|c|c|c|c|}
\hline \multirow[b]{2}{*}{ Glycan structures } & \multicolumn{9}{|c|}{$\%$ Area } \\
\hline & T-flask & $\mathrm{CY} 1$ & $\mathrm{CY} 2$ & $\mathrm{CY} 3$ & $\mathrm{CY} 4$ & CY5 & $\mathrm{CY} 6$ & $\mathrm{CY} 7$ & CYS \\
\hline Total peaks & 17 & 17 & 20 & 19 & 19 & 17 & 20 & 15 & 11 \\
\hline Agalactosylated (G0) & 46.67 & 29.35 & 23.64 & 28.35 & 30.41 & 34.06 & 25.16 & 36.56 & 39.70 \\
\hline Galactosylated (G1+G2+G3) & 53.34 & 70.65 & 76.37 & 71.63 & 69.58 & 65.93 & 74.85 & 63.42 & 60.31 \\
\hline Monogalactosylated (G1) & 36.11 & 48.69 & 38.59 & 39.64 & 42.85 & 45.34 & 40.65 & 43.06 & 49.74 \\
\hline Digalactosylated (G2) & 14.06 & 20.48 & 27.45 & 23.02 & 21.13 & 18.25 & 26.29 & 18.97 & 10.57 \\
\hline Trigalactosylated (G3) & 3.17 & 1.49 & 10.33 & 8.97 & 5.61 & 2.35 & 7.91 & 1.40 & 0.00 \\
\hline Core fucosylated (F) & 89.01 & 78.74 & 72.06 & 73.63 & 73.36 & 54.90 & 72.19 & 88.89 & 71.71 \\
\hline Core fucosylated agalactosylated (FG0) & 40.99 & 22.01 & 16.59 & 20.59 & 21.24 & 16.93 & 16.87 & 30.92 & 27.57 \\
\hline Core fucosylated monogalactosylated (FG1) & 35.36 & 38.08 & 28.31 & 29.48 & 31.91 & 23.39 & 29.93 & 40.54 & 34.87 \\
\hline Core fucosylated digalactosylated (FG2) & 10.33 & 17.16 & 20.55 & 17.71 & 16.48 & 12.23 & 20.31 & 16.03 & 9.27 \\
\hline Core fucosylated trigalactosylated (FG3) & 2.33 & 1.49 & 6.61 & 5.85 & 3.73 & 2.35 & 5.08 & 1.40 & 0.00 \\
\hline Sialylated (S1+S2+S3) & 10.73 & 8.18 & 27.14 & 23.07 & 15.78 & 14.07 & 22.77 & 7.75 & 1.56 \\
\hline Monosialylated (S1) & 4.62 & 4.71 & 6.68 & 6.13 & 5.12 & 6.93 & 7.28 & 3.87 & 1.56 \\
\hline Disialylated (\$2) & 5.00 & 3.47 & 17.92 & 14.93 & 9.32 & 7.14 & 13.70 & 3.88 & 0.00 \\
\hline Trisialylated (S3) & 1.11 & 0.00 & 2.54 & 2.01 & 1.34 & 0.00 & 1.79 & 0.00 & 0.00 \\
\hline Monosialylated monogalactosylated (S1G1) & 2.73 & 2.16 & 2.18 & 1.91 & 1.83 & 2.86 & 2.54 & 1.72 & 1.56 \\
\hline Monosialylated digalactosylated (S1G2) & 1.89 & 2.55 & 4.50 & 4.22 & 3.29 & 4.07 & 4.74 & 2.15 & 0.00 \\
\hline Monosialylated trigalactosylated (S1G3) & 0.00 & 0.00 & 0.00 & 0.00 & 0.00 & 0.00 & 0.00 & 0.00 & 0.00 \\
\hline Disialylated digalactosylated (S2G2) & 2.94 & 1.98 & 10.13 & 7.97 & 5.05 & 4.79 & 7.58 & 2.48 & 0.00 \\
\hline Disialylated trigalactosylated (S2G3) & 2.06 & 1.49 & 7.79 & 6.96 & 4.27 & 2.35 & 6.12 & 1.40 & 0.00 \\
\hline Trisialylated trigalactosylated (S3G3) & 1.11 & 0.00 & 2.54 & 2.01 & 1.34 & 0.00 & 1.79 & 0.00 & 0.00 \\
\hline Complex glycans & 98.43 & 97.74 & 98.09 & 97.81 & 97.62 & 96.81 & 97.76 & 97.87 & 97.30 \\
\hline High mannose & 1.58 & 2.26 & 1.92 & 2.19 & 2.38 & 3.19 & 2.25 & 2.13 & 2.71 \\
\hline
\end{tabular}

The major structures are marked in bold. rocking methodology, $60 \mathrm{rpm}$ enables the production of mAbs with lower levels of sialylation (reduced S2 structures) compared to $40 \mathrm{rpm}$ (CY1 versus CY3), which are potentially more effective through ADCC. However, using a continuous rocking (CY2 versus CY4), these observations are reversed, and $40 \mathrm{rpm}$ (CY4) appears as the advantageous rocking speed. There seems to be no correlation between these results and the cell concentrations and productivities achieved in these assays (Table 2). Nevertheless, the combination of rocking speed and mechanism should be considered for mAb quality.

It is mentioned in the literature that the success of the microcarrier culture is dependent on the initial colonization of the microcarriers with the cells (Blüml 2007; Butler 1996; Voigt and Zintl 1999), so the culture conditions during the first hours of culture should be optimized to improve this initial cell adhesion. In this work, two parameters that have been related to the efficiency of initial cell adhesion were assessed, namely the rocking methodology used for the first six hours of culture and the volume of the culture at inoculation. 
Regarding the rocking methodology, it was found that this culture parameter affects the glycosylation profile, but diverges with the concentration of cell inoculum used. Indeed, when using $2 \times 10^{5}$ cells $/ \mathrm{mL}$ (CY1 versus CY2), continuous rocking resulted in increased levels of sialylation, mainly due to a higher presence of S2 structures, which potentially results in a less efficient $\mathrm{mAb}$ due to a decreased ADCC activity. However, when using a cell inoculum of $4 \times 10^{5}$ cells/mL (CY6 versus CY7), the continuous rocking leads to a mAb with lower galactosylation and sialylation, and higher fucosylation, whose biological impact is difficult to predict due to the opposite effects of these functional elements, although a decline of $\mathrm{mAb}$ effectiveness would be expected due to the greater impact of fucosylation on $\mathrm{mAb}$ functionality. Nevertheless, the combination of rocking methodology at the beginning of the culture and concentration of cell inoculum seems to be important for mAb quality.

Concerning the culture volume, the use of total $(5 \mathrm{~mL})$ or half $(2.5 \mathrm{~mL})$ volume was tested (CY1 versus CY5), with half (CY5) leading to a higher sialylation (mainly due to increased S2) and to a great reduction in the levels of fucosylation. Due to the known strong impact of fucosylation on IgG activity through ADCC (Shields et al. 2002), it is expected that the positive effects associated with its reduction in these conditions will surpass the negative effects of an increased sialylation, and result in a mAb with improved activity. The use of different volumes at inoculation may affect the microenvironment of the cells and therefore influence glycosylation. Furthermore, although it has been suggested that the use of half volume during the initial hours of culture may improve cell adhesion and consequently the final cell and product yields, such effect was not observed in this study.

In addition to the functional elements already discussed, other less abundant glycoforms may also have an important effect on the biological activity of therapeutic IgGs. The presence of high mannose structures, for example, has been associated with reduced ADCC and CDC (Kanda et al. 2007), as well as with a rapid IgG clearance from serum (Abès and Teillaud 2010). In this study, the levels of high mannose are, in general, slightly increased in microcarrier cultures (particularly for CY5).

The influence of the culture vessel on the glycosylation profile of the mAb produced by $\mathrm{CHO}$ cells in microcarriers was also considered in this work, by comparing vented conical tubes with shake flasks. The culture vessel was highly influential particularly in the sialylation levels of the mAb, which abruptly decreased to practically absent sialylation in shake flasks, predicting a positive outcome on mAb biological activity. Additionally, shake flasks seem to provide a less heterogeneity of glycoforms, as demonstrated by the lowest number of peaks obtained (11 peaks, Table 3 ). Since cell concentrations are highly improved in shake flasks when compared to the vented conical tube cultures, it is possible that these improved levels, or the factors that led to them (e.g. better oxygenation and mass transfer), have caused these modifications on sialylation and heterogeneity.

Some additional cultures were performed with a different type of microcarrier, specifically the macroporous CultiSpher-S, for effects of comparison (data not shown). The global influence of CultiSpher-S cultures on glycosylation, in comparison with T-flask cultures, was similar to that previously observed with Cytodex 3 , causing a general reduction on the percentage of main structures, an increase of galactosylation, a slightly reduction of fucosylation, and a variable effect on sialylation. Furthermore, two culture variables tested with CultiSpher-S (initial culture volume and culture vessel) also demonstrated effects on glycosylation similar to those of Cytodex 3 cultures. Of note is the strong impact of the culture vessel on the glycosylation profile obtained with both microcarrier cultures, with shake flasks confirming to be the best option by decreasing the heterogeneity of glycoforms and leading to remarkable decreases of mAb sialylation with CultiSpher-S. The cell densities achieved on these microcarriers were also significantly improved in shake flasks, reinforcing the possibility of this being the cause for the positive changes observed in the glycosylation profile of the mAb.

\section{Conclusions}

An understanding of the role of culture conditions on glycosylation is becoming increasingly important to ensure a consistent quality of the product. In this study, the effect of microcarrier culture and different culture conditions on the glycosylation pattern of a mAb produced by $\mathrm{CHO}-\mathrm{K} 1$ cells was evaluated. Higher levels of galactosylation (main di- and trigalacto structures) and lower degrees of fucosylation were found in mAb produced in microcarriers when compared to the typical T-flask culture, both potentially improving the mAb effectiveness. On the other hand, sialylation was found to be highly variable without a specific tendency. Furthermore, contrary to what has been suggested, the increased productivities obtained in microcarrier cultures did not correlate with a lower quality of the $\mathrm{mAb}$. On the other hand, the fact that microcarrier cultures are performed under rocking conditions, as opposed to T-flask cultures, and the possible creation of specific microenvironments in the microcarriers may be a cause for the divergences found between them in the glycosylation profile of the mAb produced.

All the culture conditions assessed in microcarrier culture led to modifications on the mAb glycan profile, with each of the functional elements (galactose, core fucose and sialic acid) being divergently affected by these conditions. In particular, the choice of the culture vessel 
appears to have a strong influence in mAb sialylation, with great and desirable reductions achieved in shake flask cultures. This is potentially related to highly improved cell densities achieved in these vessels, which may have also been the cause for a reduction of the glycoform heterogeneity of the mAb.

\section{Methods}

\section{Cell line and cell preparation}

A CHO-K1 cell line (obtained from American Type Culture Collection) previously transfected for the production of a recombinant human mAb (CAB051 from Biotecnol SA, Lisbon, with application on cancer therapy) was used (Costa et al. 2012). These cells were grown in Dulbecco's Modified Eagle Medium (DMEM, Sigma-Aldrich) supplemented with $10 \%$ fetal bovine serum (FBS, SigmaAldrich) and $1 \times$ hypoxanthine-aminopterin-thymidine (HAT, Sigma-Aldrich), at $37^{\circ} \mathrm{C}$ and $5 \% \mathrm{CO}_{2}$, in $75 \mathrm{~cm}^{2}$ culture flasks (T-flasks). For the microcarrier cultures, cells were detached after reaching $70-80 \%$ confluence, and the concentration of the cell suspension adjusted to the values needed for each assay.

\section{Microcarrier preparation}

The microporous Cytodex 3 (Sigma-Aldrich) was used in this work, and prepared according to manufacturer instructions. Briefly, the dry microcarriers were swollen and hydrated in calcium- and magnesium-free phosphate buffered saline $(\mathrm{Ca} / \mathrm{Mg}$-free $\mathrm{PBS}, 137 \mathrm{mM}$ sodium chloride, $2.7 \mathrm{mM}$ potassium chloride, $10 \mathrm{mM}$ sodium phosphate dibasic, and $2 \mathrm{mM}$ potassium phosphate monobasic, $\mathrm{pH} 7.4$, Sigma-Aldrich) for at least $3 \mathrm{~h}$ at room temperature, sterilized $\left(121^{\circ} \mathrm{C}, 15 \mathrm{~min}, 15 \mathrm{psi}\right)$, and stored at $4^{\circ} \mathrm{C}$. Prior to use, the sterilized microcarriers were washed twice with culture medium and once with $\mathrm{Ca} / \mathrm{Mg}$-free PBS.

\section{Microcarrier culture}

Microcarrier cultures were initially performed in $50 \mathrm{~mL}$ vented conical tubes (INOPAT) and later in $250 \mathrm{~mL}$ shake flasks (Sigma-Aldrich).
In vented conical tubes, $5 \mathrm{~mL}$ cultures of $\mathrm{CHO}-\mathrm{K} 1$ cells were performed with $3 \mathrm{~g} / \mathrm{L}$ of Cytodex 3 , and different culture conditions were assessed, as described in Table 4. All cultures were maintained at $37^{\circ} \mathrm{C}$ and $5 \%$ $\mathrm{CO}_{2}$, in a support that ensured a fixed $30^{\circ}$ inclination angle, placed on an orbital rocking platform. The assays using half the volume of medium at inoculation were completed with the remaining volume after the first $6 \mathrm{~h}$ of culture (considered the critical phase for initial cell adhesion). For all assays, the medium was renewed daily by replacing half of the culture volume with fresh growth medium.

In shake flasks, cultures of $20 \mathrm{~mL}$ of $\mathrm{CHO}-\mathrm{K} 1$ cells were performed as described for the vented conical tubes, with the exception of the $30^{\circ}$ inclination.

\section{Culture monitoring}

Cell growth was monitored for T-flask and Cytodex 3 cultures. Cells were released from the microcarriers by enzymatic digestion with trypsin (Sigma-Aldrich) and enumerated in a hematocytometer with trypan blue staining (Sigma-Aldrich), for viability assessment. In microcarrier cultures, the cell concentration in the sample was standardized with the number of microcarriers counted microscopically in the sample, and the concentration of cells per microcarrier $\left(\mathrm{C}_{\text {cell/microcarrier }}\right)$ determined according to Equation 1.

$$
C_{\text {cell } / \text { microcarrier }}=\frac{\left[\left(N_{\text {cell }} / 4\right) \times 10^{4}\right] \times F \times V_{\text {sample }}}{N_{\text {microcarriers in sample }}}
$$

Where $\mathrm{N}_{\text {cell }}$ is the total number of cells counted in the hematocytometer, $\mathrm{F}$ the sample dilution factor, $\mathrm{V}_{\text {sample }}$ the volume of the sample in $\mathrm{mL}$, and $\mathrm{N}_{\text {microcarriers in sample }}$ the total number of microcarriers counted in the sample.

The cell concentration in the culture $\left(\mathrm{C}_{\text {cell } / \mathrm{mL}}\right)$ was then determined according to Equation 2.

$$
C_{\text {cell } / m L}=C_{\text {cell/microcarrier }} \times C_{\text {microcarriers } / m L}
$$

Where $\mathrm{C}_{\text {cell/microcarrier }}$ is the cell concentration per microcarrier, and $\mathrm{C}_{\text {microcarriers } / \mathrm{mL}}$ is the microcarrier

\begin{tabular}{|c|c|c|c|c|c|}
\hline Assay & Inoculum concentration (cells/mL) & Rocking mechanism & Rocking speed (rpm) & Volume at inoculation & Culture vessel \\
\hline CY1 & $2 \times 10^{5}$ & Pulse followed by continuous ${ }^{a}$ & 60 & Total & Vented conical tube \\
\hline $\mathrm{CY} 2$ & $2 \times 10^{5}$ & Continuous & 60 & Total & Vented conical tube \\
\hline CY3 & $2 \times 10^{5}$ & Pulse followed by continuous ${ }^{a}$ & 40 & Total & Vented conical tube \\
\hline CY4 & $2 \times 10^{5}$ & Continuous & 40 & Total & Vented conical tube \\
\hline CY5 & $2 \times 10^{5}$ & Pulse followed by continuous ${ }^{a}$ & 60 & Half & Vented conical tube \\
\hline CY6 & $4 \times 10^{5}$ & Pulse followed by continuous ${ }^{\text {a }}$ & 60 & Total & Vented conical tube \\
\hline CY7 & $4 \times 10^{5}$ & Continuous & 60 & Total & Vented conical tube \\
\hline CYS & $4 \times 10^{5}$ & Pulse followed by continuous ${ }^{a}$ & 60 & Total & Shake flask \\
\hline
\end{tabular}

Table 4 Conditions tested for the culture of monoclonal antibody-producing CHO-K1 cells in Cytodex 3 microcarriers

${ }^{a}$ Pulse rocking (60 or $40 \mathrm{rpm}$ for $1 \mathrm{~min}$ at each $30 \mathrm{~min}$ ) during the first six hours of culture, followed by continuous rocking for the remaining time of culture. 
concentration in microcarriers per $\mathrm{mL}$ as obtained from Equation 3.

$$
\begin{aligned}
C_{\text {microcarriers } / m L}= & C_{\text {microcarriers in } g / m L} \\
& \times N_{\text {microcarriers } / g d r y \text { weight }}
\end{aligned}
$$

Where $\mathrm{C}_{\text {microcarriers }}$ in $\mathrm{g} / \mathrm{mL}$ is the concentration of microcarriers used in the culture in grams of dry weight per $\mathrm{mL}$, and $\mathrm{N}_{\text {microcarriers/g dry weight }}$ is the approximate number of microcarriers per gram of dry weight (data provided by the manufacturer).

\section{Antibody quantification}

Cell productivity was assessed by enzyme linked immunosorbent assay (ELISA), following an optimized procedure of Biotecnol SA (Portugal). Briefly, dilutions of the samples, a standard of known concentration, and a quality control were added to 96 well plates previously coated with capture antibody. After incubation for $2 \mathrm{~h}$ at $37^{\circ} \mathrm{C}$, a detection antibody was added and the plates further incubated for $2 \mathrm{~h}$ at room temperature. A 3,3',5,5'Tetramethylbenzidine (TMB, Sigma-Aldrich) substrate solution was then added and allowed to react for $10 \mathrm{~min}$, at room temperature, the reaction stopped, and the absorbance read at $450 \mathrm{~nm}$. The concentration of $\mathrm{mAb}\left(\mathrm{C}_{\mathrm{mAb}}\right.$, in $\left.\mu \mathrm{g} / \mathrm{mL}\right)$ in each sample was determined by Equation 4 and the productivity ( $\mathrm{q}_{\mathrm{mAb}}$, in $\mathrm{pg} /$ cell/day) calculated according to Equation 5.

$$
C_{\mathrm{mAb}}=\left(\left(\frac{a-d}{\mathrm{Abs}_{450}-d}\right)-1\right)^{\frac{1}{b}} \times c
$$

Where $\mathrm{Abs}_{450}$ is the absorbance read at $450 \mathrm{~nm}$, a the estimated response at zero concentration, $b$ the slope factor, c the mid-range concentration, $d$ the estimated response at infinite concentration (parameters determined using the $\mathrm{R}$ software, version 2.6.2, from the $\mathrm{R}$ Foundation for Statistical Computing).

$$
q_{m A b}(p g / c e l l / \text { day })=\frac{C_{m A b} / C_{c e l l} / m L}{t} \times 10^{6}
$$

Where $t$ is the time of production in days.

\section{$\mathrm{N}$-glycosylation analysis}

The glycosylation profile of the mAb obtained from the T-flask and microcarrier cultures at different conditions was assessed.

\section{IgG purification}

Prior to IgG purification, samples were concentrated to volumes of $200 \mu \mathrm{L}$ using $15 \mathrm{~mL}$ spin concentrators of 5 $\mathrm{kDa}$ molecular weight cutoff (Agilent Technologies). Then, the IgG from the concentrated samples was purified with Protein A spin plates (Thermo Scientific) according to manufacturer instructions, with slight modifications. Briefly, the wells of a spin plate were equilibrated with Binding Buffer (phosphate buffered saline, $\mathrm{pH} 7.2$ ), sample dilutions $(50 \% \mathrm{v} / \mathrm{v}$ in Binding Buffer) were added, and the plates incubated for $30 \mathrm{~min}$ with moderate agitation. The resin was then washed with Binding Buffer, and the purified IgG eluted $(0.5 \mathrm{M}$ acetic acid, $\mathrm{pH} 2.5$ ) and neutralized (1 $\mathrm{M}$ ammonium bicarbonate, $\mathrm{pH}$ 7-8.5). The elutions containing the purified antibody were dried overnight.

\section{In gel block immobilization}

The dried samples were reduced with a solution containing $13.88 \mathrm{mM}$ sodium dodecyl sulfate (SDS), $12.5 \mathrm{mM}$ Tris (pH 6.6) and $0.05 \mathrm{M}$ dithiothreitol (DTT) for $15 \mathrm{~min}$ at $65^{\circ} \mathrm{C}$; and alkylated with $100 \mathrm{mM}$ iodoacetamide (IAA) for $30 \mathrm{~min}$ in the dark. Then, gel blocks were formed by adding a mixture of $22.5 \mu \mathrm{L}$ of Protogel $30 \%, 11.25 \mu \mathrm{L}$ of $1.5 \mathrm{M}$ Tris $(\mathrm{pH} 8.8), 1 \mu \mathrm{L}$ of $35 \mathrm{mM}$ SDS, and $1 \mu \mathrm{L}$ of $34.7 \mathrm{mM}$ ammonium peroxisulphate solution (APS), and finally adding $1 \mu \mathrm{L}$ of tetramethylethylenediamine (TEMED) to the samples, letting set for $15 \mathrm{~min}$. The in gel block immobilization of the glycoprotein allows an easier removal of the reducing and alkylating agents, as well as of buffers and environmental contaminants, increasing the efficacy of the enzymatic release of the monosaccharides.

\section{$\mathrm{N}$-glycan release and fluorescent labeling}

Each gel block was cut into small pieces $\left(\approx 2 \mathrm{~mm}^{2}\right)$, washed alternately with acetonitrile and $20 \mathrm{mM}$ sodium bicarbonate $(\mathrm{pH} 7)$, and dried in a vacuum centrifuge. For the release of $N$-linked glycans, the dried gel pieces were incubated for $15 \mathrm{~min}$ in $50 \mu \mathrm{L}$ of a PNGase F (Prozyme) solution ( $4 \% \mathrm{v} / \mathrm{v}$ in $20 \mathrm{mM}$ sodium bicarbonate (pH 7)), and a further $12-16 \mathrm{~h}$ at $37^{\circ} \mathrm{C}$ after adding extra $50 \mu \mathrm{L}$ of $20 \mathrm{mM}$ sodium bicarbonate. The supernatant was then removed (13,000 rpm, $5 \mathrm{~min})$, and the samples subjected to a series of washes with water and acetonitrile, with a $15 \mathrm{~min}$ sonication for each wash. The supernatants obtained were collected and dried in a vacuum centrifuge. The dried samples were redissolved in $20 \mu \mathrm{L}$ formic acid (1\%), incubated for $40 \mathrm{~min}$ at room temperature and dried in a vacuum centrifuge.

The released $N$-glycans were labeled for fluorescent detection using the LudgerTag ${ }^{\mathrm{TM}}$ 2-aminobenzamide (2AB) Glycan Labeling Kit (Ludger), according to manufacturer instructions. Briefly, $5 \mu \mathrm{L}$ of the $2 \mathrm{AB}$ labeling mix were added to each dried glycan sample, incubated $30 \mathrm{~min}$ at $65^{\circ} \mathrm{C}$, vortexed, spun down, and incubated for further $90 \mathrm{~min}$.

The excess $2 \mathrm{AB}$ label from labeled $\mathrm{N}$-glycans was cleaned-up using Normal Phase 1 PhyNexus tips (PhyNexus). Briefly, samples were diluted in $95 \mu \mathrm{L}$ water and $900 \mu \mathrm{L}$ acetonitrile. The PhyNexus tips were prepared 
by a series of ten uptake washes with $95 \%$ acetonitrile (v/v in water), $20 \%$ acetonitrile $(\mathrm{v} / \mathrm{v}$ in water) and again 95\% acetonitrile. Samples were loaded into the PhyNexus tips through ten in-out cycles, followed by ten uptake washes with $95 \%$ acetonitrile. The glycans were then eluted with five uptake rounds of $20 \%$ acetonitrile, and the elutions collected and dried in a vacuum centrifuge.

\section{Normal phase-high performance liquid chromatography}

For normal phase-high performance liquid chromatography (NP-HPLC), each dried sample was ressuspended in $20 \mu \mathrm{L}$ water and $80 \mu \mathrm{L}$ acetonitrile. NP-HPLC was performed using a TSKgel Amide-80 $3 \mu \mathrm{m}(150 \times$ $4.6 \mathrm{~mm}$ ) column (Tosoh Bioscience) for $60 \mathrm{~min}$ runs, at $30^{\circ} \mathrm{C}$, using $50 \mathrm{mM}$ ammonium formate as Solvent A and acetonitrile as Solvent B. The runs were performed on a 2695 Alliance separations module (Waters) with a 2475 multi-wavelenght fluorescence detector (Waters), with excitation and emission wavelengths at 330 and $420 \mathrm{~nm}$, respectively. Conditions of the $60 \mathrm{~min}$ method were a linear gradient of 35 to $47 \%$ Solvent A over $48 \mathrm{~min}$ at a flow rate of $0.48 \mathrm{~mL} / \mathrm{min}$, followed by a min at 47 to $100 \%$ Solvent A and $4 \mathrm{~min}$ at $100 \%$ Solvent A, returning to $35 \%$ solvent $\mathrm{A}$ over $1 \mathrm{~min}$ and then finishing with 35\% solvent A for 6 min.

The systems were calibrated by running an external standard of 2-AB dextran ladder (2-AB labeled glucose homopolymer) alongside the sample runs.

\section{Processing of samples}

A fifth-order polynomial distribution curve was fitted to the dextran ladder and used to allocate glucose unit (GU) values from retention times, using Empower GPC software (Waters). Tentative assignment of structures to the peaks was then made by matching the $G U$ values obtained with those in GlycoBase (http://glycobase.nibrt. ie/), and using the known IgG1 profile as a guide. The relative percentage of $\mathrm{N}$-linked glycans was then calculated for agalactosylated (G0), monogalactosylated (G1), digalactosylated (G2), trigalactosylated (G3), galactosylated $(\mathrm{G} 1+\mathrm{G} 2+\mathrm{G} 3)$, core fucosylated $(\mathrm{F})$, core fucosylated agalactosylated (FG0), core fucosylated monogalactosylated (FG1), core fucosylated digalactosylated (FG2), core fucosylated trigalactosylated (FG3), monosialylated (S1), disialylated (S2), trisialylated ( $\mathrm{S} 3)$, sialylated $(\mathrm{S} 1+\mathrm{S} 2+\mathrm{S} 3)$, monosialylated monogalactosylated (S1G1), monosialylated digalactosylated (S1G2), monosialylated trigalactosylated (S1G3) disialylated digalactosylated (S2G2), disialylated trigalactosylated (S2G3), trisialylated trigalactosylated (S3G3), high mannose, and complex glycan structures. The relative percentages were determined by summing the percentage of area of the peaks pertaining to each of the abovementioned structures.

\section{Competing interests}

The authors declare that they have no competing interests.

\section{Authors' contributions}

ARC carried out the microcarrier culture experiments and the glycosylation studies, and drafted the manuscript. JW participated in the glycosylation analysis and helped to draft the manuscript. MER carried out the microcarrier experiments and helped to draft the manuscript. NM participated in the glycosylation analysis. MH, RO, PMR and JA participated in the design and coordination of the study, and helped to draft the manuscript. All authors read and approved the final manuscript.

\section{Aknowledgments}

The authors acknowledge funding and support from the Portuguese Foundation for Science and Technology (FCT), namely grant reference SFRH/ BD/46660/2008 for Ana Rita Costa and SFRH/BD/46661/2008 for Maria Elisa Rodrigues. A special acknowledgment to Biotecnol S.A. (Lisbon, Portugal) for providing the monoclonal antibody used in this study.

\section{Author details}

${ }^{1}$ IBB-Institute for Biotechnology and Bioengineering, Centre of Biological Engineering, University of Minho, Campus de Gualtar, 4710-057, Braga, Portugal. ${ }^{2}$ NIBRT Dublin-Oxford Glycobiology Laboratory, National Institute for Bioprocessing Research and Training, Fosters Avenue, Mount Merrion, Blackrock, Co. Dublin, Ireland.

Received: 22 November 2012 Accepted: 23 January 2013 Published: 28 January 2013

\section{References}

Abès R, Teillaud J-L (2010) Impact of glycosylation on effector functions of therapeutic lgG. Pharmaceuticals 3:146-157

Almgren J, Nilsson C, Peterson AC, Nilsson K (1991) Cultispher-macroporous gelatine microcarrier-new applications. In: Spier RE, Griffiths JB, Meignier B (ed) Production of biologicals from animal cells in culture. Butterworth-Heinemann, Oxford

Anthony R, Ravetch J (2010) A novel role for the IgG Fc glycan: the antiinflammatory activity of sialylated IgG Fcs. J Clin Immunol 30:9-14

Anthony RM, Nimmerjahn F, Ashline DJ, Reinhold VN, Paulson JC, Ravetch JV (2008) Recapitulation of IVIG anti-inflammatory activity with a recombinant lgG Fc. Science 320:373-376

Arnold JN, Wormald MR, Sim RB, Rudd PM, Dwek RA (2007) The impact of glycosylation on the biological function and structure of human immunoglobulins. An Rev Immunol 25:21-50

Berry JM, Barnabé N, Coombs KM, Butler M (1999) Production of reovirus type-1 and type-3 from Vero cells grown on solid and macroporous microcarriers. Biotechnol Bioeng 62:12-19

Blüml G (2007) Microcarrier Cell Culture Technology. In: Pörtner R (ed) Animal cell biotechnology: methods and protocols, 2nd edition. Humana Press Inc., Totowa, NJ

Butler M (1996) Chapter 10 - Modes of culture for high cell densities. In: Butler M (ed) Animal cell culture and technology. Taylor and Francis, Routledge, UK

Butler M, Burgener A, Patrick M, Berry M, Moffatt D, Huzel N, Barnabé N, Coombs K (2000) Application of a serum-free medium for the growth of Vero cells and the production of reovirus. Biotechnol Bioeng 16:854-858

Chu L, Robinson DK (2001) Industrial choices for protein production by largescale cell culture. Cur Opin Biotechnol 12:180-187

Cosgrove L, Lovrecz GO, Verkuylen A, Cavaleri L, Black LA, Bentley JD, Howlett GJ, Gray PP, Ward CW, McKern NM (1995) Purification and properties of insulin receptor ectodomain from large-scale mammalian cell culture. Protein Expression Purif 6:789-798

Costa AR, Rodrigues ME, Henriques M, Melton D, Cunnah P, Oliveira R, Azeredo J (2012) Evaluation of the OSCAR ${ }^{\mathrm{TM}}$ system for the production of monoclonal antibodies by CHO-K1 cells. Int J Pharm 430:42-46

Gramer MJ, Goochee CF (1993) Glycosidase activities in Chinese hamster ovary cell lysate and cell culture supernatant. Biotechnol Prog 9:366-373

Hirtenstein M, Clark J, Lindgren G, Vretblad P (1980) Microcarriers for animal cell culture: a brief review of theory and practice. Dev Biol Stand 46:109-116

Hodoniczky J, Zheng YZ, James DC (2005) Control of recombinant monoclonal antibody effector functions by Fc N-glycan remodeling in vitro. Biotechnol Prog 21:1644-1652 
Hooker AD, Goldman MH, Markham NH, James DC, Ison AP, Bull AT, Strange PG, Salmon I, Baines AJ, Jenkins N (2007) Monitoring recombinant human interferon-gamma N-glycosylation during perfused fluidized-bed and stirred-tank batch culture of CHO cells. Biotechnol Bioeng 48:596-607

Hu X, Xiao C, Huang Z, Guo Z, Zhang Z, Li Z (2000) Pilot production of u-PA with porous microcarrier cell culture. Cytotechnology 33:13-19

Jefferis R, Lund J (1997) Glycosylation of antibody molecules: structural and functional significance. Chem Immunol 65:111-128

Jenkins N, Curling E (1994) Glycosylation of recombinant proteins: problems and prospects. Enzyme Microb Technol 16:354-364

Kanda Y, Yamada T, Mori K, Okazaki A, Inoue M, Kitajima-Miyama K, Kuni-Kamochi R, Nakano R, Yano K, Kakita S, Shitara K, Satoh M (2007) Comparison of biological activity among nonfucosylated therapeutic $\lg \mathrm{G} 1$ antibodies with three different N-linked Fc oligosaccharides: the high-mannose, hybrid, and complex types. Glycobiology 17:104-118

Kaneko Y, Nimmerjahn F, Ravetch JV (2006) Anti-inflammatory activity of immunoglobulin G resulting from Fc sialylation. Science 313:670-673

Kong D, Chen M, Gentz R, Zhang J (1999) Cell growth and protein formation on various microcarriers. Cytotechnology 29:151-158

Kumpel B, Rademacher T, Rook G, Williams P, Wilson I (1994) Galactosylation of human IgG monoclonal anti-D produced by EBV-transformed Blymphoblastoid cell lines is dependent on culture method and affects FC receptor-mediated functional activity. Hum Antibodies Hybridomas 5:143-151

Mendonça R, loshimoto L, Mendonça R, De-Franco M, Valentini E, Beçak W, Raw I, Pereira C (1993) Preparation of human rabies vaccine in VERO cell culture using a microcarrier system. Braz J Med Biol Res 26:1305-1317

Nam JH, Zhang F, Ermonval M, Linhardt RJ, Sharfstein ST (2008) The effects of culture conditions on the glycosylation of secreted human placental alkaline phosphatase produced in Chinese hamster ovary cells. Biotechnol Bioeng 100:1178-1192

Ng YC, Berry JM, Butler M (1996) Optimization of physical parameters for cell attachment and growth on macroporous microcarriers. Biotechnol Bioeng 50:627-635

Nilsson K, Buzsaky F, Mosbach K (1986) Growth of anchorage-dependent cells on macroporous microcarriers. Nat Biotech 4:989-990

Ozturk SS, Hu W-S (2006) Cell Culture Technology for Pharmaceutical and Cell-Based Therapies. CRC Press, New York

Pučić M, Knežević A, Vidič J, Adamczyk B, Novokmet M, Polašek O, Gornik O, Šupraha-Goreta S, Wormald MR, Redžić I, Campbell H, Wright A, Hastie ND, Wilson JF, Rudan I, Wuhrer M, Rudd PM, Josić D, Lauc G (2011) High throughput isolation and glycosylation analysis of lgG-variability and heritability of the IgG glycome in three isolated human populations. Mol Cell Proteomics 10:M111.010090

Rudolph G, Lindner P, Gierse A, Bluma A, Martinez G, Hitzmann B, Scheper T (2008) Online monitoring of microcarrier based fibroblast cultivations with in situ microscopy. Biotechnol Bioeng 99:136-145

Scallon BJ, Tam SH, McCarthy SG, Cai AN, Raju TS (2007) Higher levels of sialylated Fc glycans in immunoglobulin $\mathrm{G}$ molecules can adversely impact functionality. Mol Immunol 44:1524-1534

Schürch U, Cryz SJ, Lang AB (1992) Scale-up and optimization of culture conditions of a human heterohybridoma producing serotype-specific antibodies to Pseudomonas aeruginosa. Appl Microbiol Biotechnol $37: 446-450$

Serrato JA, Hernández V, Estrada-Mondaca S, Palomares LA, Ramírez OT (2007) Differences in the glycosylation profile of a monoclonal antibody produced by hybridomas cultured in serum-supplemented, serum-free or chemically defined media. Biotechnol Appl Biochem 47:113-124

Shields RL, Lai J, Keck R, O'Connell LY, Hong K, Meng YG, Weikert SHA, Presta LG (2002) Lack of fucose on human IgG1 N-linked oligosaccharide improves binding to human FcyRIII and antibody-dependent cellular toxicity. J Biol Chem 277:26733-26740

Shinkawa T, Nakamura K, Yamane N, Shoji-Hosaka E, Kanda Y, Sakurada M, Uchida K, Anazawa H, Satoh M, Yamasaki M, Hanai N, Shitara K (2003) The absence of fucose but not the presence of galactose or bisecting $\mathrm{N}$ acetylglucosamine of human lgG1 complex-type oligosaccharides shows the critical role of enhancing antibody-dependent cellular cytotoxicity. J Biol Chem 278:3466-3473

Sibéril S, de Romeuf C, Bihoreau N, Fernandez N, Meterreau J-L, Regenman A, Nony E, Gaucher C, Glacet A, Jorieux S, Klein P, Hogarth MP, Fridman W-H, Bourel D, Béliard R, Teillaud J-L (2006) Selection of a human anti-RhD monoclonal antibody for therapeutic use: Impact of IgG glycosylation on activating and inhibitory FcyR functions. Clin Immunol 118:170-179

Spearman M, Rodriguez J, Huzel N, Butler M (2005) Production and glycosylation of recombinant $\beta$-interferon in suspension and cytopore microcarrier cultures of $\mathrm{CHO}$ cells. Biotechnol Prog 21:31-39

Van Wezel AL (1967) Growth of cell-strains and primary cells on micro-carriers in homogeneous culture. Nature 216:64-65

Voigt A, Zintl F (1999) Hybridoma cell growth and anti-neuroblastoma monoclonal antibody production in spinner flasks using a protein-free medium with microcarriers. J Biotechnol 68:213-226

Wang MD, Yang M, Huzel N, Butler M (2002) Erythropoietin production from $\mathrm{CHO}$ cells grown by continuous culture in a fluidized-bed bioreactor. Biotechnol Bioeng 77:194-203

Wang Y, Ouyang F (1999) Bead-to-bead transfer of Vero cells in microcarrier culture. Bioproc Biosys Eng 21:211-213

Watson E, Shah B, Leiderman L, Hsu Y-R, Karkare S, Lu HS, Lin F-K (1994) Comparison of $\mathrm{N}$-linked oligosaccharides of recombinant human tissue kallikrein produced by Chinese hamster ovary cells on microcarrier beads and in serum-free suspension culture. Biotechnol Prog 10:39-44

Wu S-C, Hsieh W-C, Liau M-Y (1998) Comparisons of microcarrier cell culture processes in one hundred mini-liter spinner flask and fifteen-liter bioreactor cultures. Bioproc Eng 19:431-434

Wu S-C, Huang GY-L (2002) Stationary and microcarrier cell culture processes for propagating japanese encephalitis virus. Biotechnol Prog 18:124-128

Wu S-C, Huang GY-L, Liu J-H (2002) Production of retrovirus and adenovirus vectors for gene therapy: a comparative study using microcarrier and stationary cell culture. Biotechnol Prog 18:617-622

Yokomizo AY, Antoniazzi MM, Galdino PL, Azambuja N, Jorge SAC, Pereira CA (2004) Rabies virus production in high vero cell density cultures on macroporous microcarriers. Biotechnol Bioeng 85:506-515

Ziao C, Huang Z, Li W, Hu X, Qu W, Gao L, Liu G (2002) High density and scaleup cultivation of recombinant Cho cell line and hybridomas with porous microcarrier cytopore. In: Merten O-W, Perrin P, Griffiths B (ed) New developments and new applications in animal cell technology. Kluwer Academic Publishers, New York

doi:10.1186/2193-1801-2-25

Cite this article as: Costa et al:: The impact of microcarrier culture optimization on the glycosylation profile of a monoclonal antibody. SpringerPlus 2013 2:25.

\section{Submit your manuscript to a SpringerOpen ${ }^{\circ}$ journal and benefit from:}

- Convenient online submission

- Rigorous peer review

- Immediate publication on acceptance

- Open access: articles freely available online

- High visibility within the field

- Retaining the copyright to your article

Submit your next manuscript at springeropen.com 